\title{
The Repressive Hypothesis: Natural Sexuality, Suppressed Eros and a Chance of an Alternative?
}

\author{
Philipp Tagirov \\ Department of Social Philosophy \\ Peoples Friendship University of Russia \\ Moscow, Russia \\ E-mail: tagirov_fv@ rudn.university
}

\begin{abstract}
The article studies the so called "repressive hypothesis" according to which eros and sexuality are suppressed by authoritarian social order. This hypothesis is based of Freudian idea of repressive nature of culture and developed primarily by W. Reich and G. Marcuse. The current analysis points out the main elements of this theory such as the object of suppression, the roots of authoritarian society, general mechanics of repression and the possibilities for nonrepressive social order.
\end{abstract}

Keywords-authoritarianism; eros; morality; repression; sexuality

\section{INTRODUCTION}

When a person in his mind overcomes (transcends) the limits of the traditional model of legitimizing power (M. Weber), he begins to see concrete forms of domination as not something absolute, given from above, everlasting (and, therefore, true and unchanging), but something historically relative, socially and culturally determined. At the same time, the principle of reality, which puts limits on person's principle of desire (S. Freud), from now on also appears to the subject of this desire to be largely historical, sociogenic and, therefore, the one that can be changed along with certain changes in social sphere.

The boundaries imposed to love, sexuality and eroticism are inevitably felt by the subject of these practices as constraining his desires, suppressing. This gives rise to the idea of repression carried out in relation to the eroticism, and the desire for a full-fledged realization of the subject in this area is directly related to the release from existing repressive mechanisms through their abolition, or at least purposeful liberalization, "humanization", consistent softening.

The totality of cultural, symbolic, political and juridical processes aimed at this liberation was called the "sexual revolution". However, it would not be unnecessary to raise the question again and again: does such liberation bring real freedom to the subject of eros, love and sexuality? Does it really expand the boundaries of the self-realization of the

This paper was financially supported by the Ministry of Education and Science of the Russian Federation on the program to improve the

competitiveness of Peoples' Friendship University (RUDN University) among the world's leading research and education centers in the 2016-2020 (The Agreement number 02.A03.21.0008). subject, and if so, what happens at the level of external (communication, representation) and internal (responsible for the formation of identity) structures that ensure the inclusion of the subject in the control mechanisms? In other words: does the liberation of sexuality, the numerous manifestations of which we observe in the contemporary world, make a person freer? And doesn't by chance the subject of this liberation become even more dependent on both his/her own sexuality and the principles regulating his subjectivity?

\section{REPRESSIVE HYPOTHESIS: THE OBJECT OF SUPPRESSION}

Perhaps the main reason for demanding the liberation of eros is the widely shared assertion of its suppression by some external authority: authoritarian morality, repressive culture, public institutions or the whole order of social organization. This idea, which M. Foucault called the "repressive hypothesis", finds its theoretical formulation in the XX century - primarily in the writings of S. Freud, W. Reich and H. Marcuse. Erich Fromm, Bertrand Russell in his "Marriage and Morals" [1] and a number of other thinkers proclaim their solidarity with it in a certain sense.

What is the main object of repression? According to $\mathrm{Z}$. Freud and G. Marcuse, all sexuality, except for the genital (taken in its reproductive meaning), feels repressed. As Freud points out, any sexuality, where there is a deviation from its reproductive purpose or where the object of desire is not leading us to reproductive genital act, characterized by society as a perverse [2. Lectures 20-21].

At the same time, as Reich shows, normal genital sexuality is also limited by the existing compulsory order. Authoritarian morality, which finds self-justification in that it protects a person from his own perverted predispositions, harmful, and often disastrous for others as well as for himself, actually generates these inclinations and "unhealthy" aspirations. Prohibited moral deviations, according to Reich, are merely substitutes of genital sexuality [3], the effect of a depressed individual looking for a "vent" when overwhelmed by his/her impossibility to practice full and healthy genital sex life.

Why does not an individual in modern society know a healthy and natural sex life? Reich believes that the main 
structures of unhealthy attitude towards sexuality are laid in childhood. The child is taught to feel shame from observation or demonstration of the sexual organs. Spying on the sexual life of parents is punishable, which puts the entire sphere of sexual relations under the sign of the forbidden. Preventing the satisfaction of children's curiosity, parents, according to Reich, mainly pursue their own interests, rather than interests of a child. They give way to their fears as the see in this curiosity a threat to their own routinized comfort and reproduce educational models that were previously applied to them. Autoerotic pleasures, natural for the child, which in the future will give way to healthy genital sexuality with the desired partner, are condemned, and parents are trying to create conditions that complicate such practices as much as possible, which secures in the child's psyche both a tense aspiration to find a way for his/her unrealized sexuality and a strong awareness of shame and viciousness of this desires. Close attention to the content of the teenager's games with his/her peers, on the one hand, contribute to the preservation of oedipal accentuations of sexual desire on his parents, and on the other, create a traumatic situation of the contradiction between the awakened needs and the impossibility of their natural satisfaction.

All this together leads to the formation of a personality for which the most natural forms of sexuality are strongly associated with something shameful and forbidden. Subsequently, such an individual, as a rule, is unable to fully find his/her self-realization in a healthy sex life, the sexuality is conjugated with various forms of violence, sadomasochistic relations of power, fetish substitution or with asexual self-elimination, which reduces sex life, for example, to marital duty or general strikes it out of the everyday experience of the subject [3].

The fundamental role in limiting the healthy sexuality of an individual, according to Reich, is also played by the traditionally patriarchal and bourgeois institution of marriage, which to some extent is always asserted in compulsory form. The main obstacles to sexual fulfillment of the individual here, as Reich states, are the strict requirements of monogamy and minimization of premarital sex life (both become a much heavier burden particularly for women's sexuality because of the "double standard") [3].

Another theoretician of the repressive hypothesis, G. Marcuse, who understands eros, like late Freud, in an extremely broad sense - as a desire for pleasure, which is not limited not only to genital pleasure and even to bodily pleasures at all, but includes, for example, the pleasure of free labor (here the Marxist roots of the theory of Marcuse are obvious), writes about the specific castration to which an individual in a repressive civilization is exposed. Unlike practices of the castration of eunuchs, for example, where the reproductive function is primarily cut off, the suppressed individual is deprived of all eroticism that does not meet the principle of reproduction of the genus. Reproduction (of the genus) and production (of goods and means of production) are two tasks that the individual must devote himself entirely to, and on the altar of which he must put any pleasure in the name of the Prometheus principle. However, Promethean ideal of self-sacrifice, which was vital to the man of the past, at the present stage of social development (including the development of the productive forces) might be dropped, as it becomes today more and more destructive for the individual, tightening the reality principle inappropriately to the social necessity [4].

\section{THE ROOTS OF THE REPRESSIVE-AUTHORITARIAN SOCIETY}

When did the repressive society begin? According to Freud, it goes back to the situation of parricide, hypothetically taking place in ancient times. Initially, eros was monopolized by some forefather, to whom all the women of the family belonged, which over time could not but arouse the envy of his numerous sons, deprived of pleasure. Having conspired, they kill their father, but soon they face the need to recreate the repressive structure of domination in order to protect the right of pleasure they have just won from the encroachments of their own children and not to repeat the fate of their father. However, after the death of the father a huge hole remains in their inner world, a void that needs to be filled. The brothers reproduce the father's figure, but this time they place it on an unattainable for the mortal, transcendental level. Since the repressive regime and its legitimation are institutionalized through morality and religion [5].

Marcuse, accepting the idea of Freud on the whole, notes that the value of this theory is not in its historical certainty, but, above all, in its ability to serve as an explanatory model. Even if the fact of murdering the forefather never happened, the order of repressive civilization is built as if parricide described by Freud really had its place in the distant past [4].

Reich, in turn, criticizes the universality of this model, specifying that it is applicable only to the societies of the patriarchal type, but not confirmed by the data of anthropologists who studied cultures built on maternal law. Russell in his work also draws our attention to the societies, where people have not yet had ideas about fatherhood [1. Chapter 2].

\section{ON REPRESSIVE CULTURE, FASCISM AND DEPERSONALIZATION}

Culture, according to Freud, is repressive to the eros of the individual, but thanks to this repression, a sublimation mechanism is triggered, which directs the energy of the libido into the creative cultural path. However, the transfer of libidinal energy from the primary sexual urge to an authoritarian figure (for example, the leader), personifying the once-lost father, with insufficient delineation of one's own Ego and ideal Super-Ego creates the basis for the formation of the psychology of the mass individual. Such a person turns his libido, separated from his immediate sexual tasks, to an external object of worship (vertical connection), and reveals the closeness (the horizontal orientation of the libido) to a mass of the same people as (s)he, which facilitates the development of his/her identity with others, whose desire is like his/her own. Thus, the transferred sexual energy directs the subject to the submission to authority, with 
which he tries to identify himself/herself and to unite with other people around this submission [6].

Reich disputes Freud's idea of sublimation as a justification of the suppression of sexual energy since Freud doesn't distinguish satisfied and unsatisfied sexuality [3]. The truly cultural potential of a person, in his opinion, is revealed only under the condition of free and full-fledged sexual life. Suppression of healthy sexuality can produce only an unhealthy culture. Opposite examples are the exception rather than the rule [3].

Current social order, according to Reich, is built on authoritarian principles that ensure its reproduction in every new generation. Suppression of the sexual freedom in childhood and adolescence form individuals, obediently submitting to authoritarian rule in adulthood - a topic, as J. Butler mentions, "that has become a preoccupation of recent political discourse" [7. P.7]. The main reason for the mass success of fascist ideologies, from the point of view of Reich, is neither the Fuehrer figure and nor the presence of socioeconomic contradictions existing in society, but rather the predominant character structure of the individual whose primary biological needs are constantly suppressed [8. Chapter 2].

Marcuse accepts that the existence of repression in relation to the principle of pleasure was structurally grounded in need, in a lack of life opportunities, from which, according to his tough destiny (Ananke), a man of the past suffered. However, in addition to suppressing the eros for the sake of redirecting the human resource to the tasks of preserving and developing the social order, all power, as Marcuse notes, also carries out the so-called "surplus suppression", through which the authorities protect themselves from any possible practices aimed at reviewing the existing repressive system. The destructiveness (the principle of Thanatos) of the modern principle of reality arises from the fact that the aggregate amount of repression (suppression along with surplus suppression), being justified at a certain stage of historical existence, becomes redundant and oppressive as society develops further and finds new opportunities for the liberation of the individual as a subject of eros [4].

The same process is inevitably reflected in the inner world of the individual: Super-Ego as an internalized controlling authority, which in a traditionally patriarchal way embodied the will of the Father, that is referred to the personal relations, in modern society turns into a reflection of impersonal regulations, which leads to the functionalization and depersonalization of both an individual, as well as his/her attitude to the possible pleasure [4].

\section{ON THE Alternative TO THE REPRESSIVE SOCIETY}

The repressive nature inherent in culture is considered by Freud as a given. The problem can only be solved at the individual level through psychoanalytic practices. Drawing attention of the reader to the study of maternal rights societies, Reich notes that human history has known examples of social organization in which the individuals have a much greater freedom to realize their natural sexuality, and advocates for the abolition of morality. Sexual morality, in his opinion, is always authoritarian, and the need for it should fall with the release of healthy sexuality of individuals in the society.

However, referring to the experience of social transformations carried out in the Soviet Union in the 1920s., as well as the difficulties encountered on the way of these changes, Reich stresses that it would be wrong to believe that the sexual revolution can be accomplished overnight or by a simple political decision. He admits that "the socialization of the individuals", which would have to release them from the pressure of authoritarian rule, can not be achieved through nationalization of life, stating with disappointment a return to the authoritarian suppression of the sexual life, when in the 1930 's the authoritarian ideology took place of the patriarchal authoritarianism.

At the same time, in spite of the gradual nature of the required changes, Reich stresses that it is still a question of the sexual revolution, and not of sexual reform, since it is necessary to produce not just certain changes in the current social order, but to overcome an authoritarian order itself. However, sexual morality cannot just be canceled, it should be replaced with what he calls the "sexual economic regulation", meaning thereby self-regulation of the individuals coming out of their normal biological needs. According to Fromm, an alternative to the present state of things could be the so-called "humanistic culture", otherwise love meets its inevitable decomposition [9. Chapter 3].

Individual's renunciation of his/her own eros for the unceasing development of the society, according to Marcuse, can no longer find the historical justification. For what a person needs a progress? Do we need a progress for its own sake or for the sake of positive changes in the conditions of our existence that progress entails? Promethean principle in the advanced industrial society turns into a serving progress for the sake of progress. Social development, according to Marcuse, is not an end in itself, it had to take a man out of the realm of necessity and to eliminate the need for constant struggle for survival. Despite the fact that the society of late capitalism constantly produces new and new needs that the individuals usually regard not as imposed, but as their own, these are artificial and non-genuine needs [10. Chapter 1]. The nowadays civilization has reached a state in which all resources to meet real human needs are present. Based on this, Marcuse argues that the historically outdated ideal of Prometheus should be contrasted with the images of Narcissus and Orpheus, expressing forms of a non-repressive eros, which are connected with the happiness of being that is not opposed to natural reality, and fully included in it, being, for which the world manifests first of all as an object of aesthetic pleasure. Remembering Turgenev's Bazarov, we can say that nature must turn from the "workshop" back to the "temple" for man.

Repression provided social order, but it's the elimination does not mean the accession of the chaos, because there are other organizing mechanisms, and one of the most important of them for the non-repressive civilization is the principle of 
the free games, applied to many forms of human interaction, which are eroticized by it. There are always rules in a game, but they are not imposed by a repressive manner and a subject accepts them for the sake of pleasure he gets from his/her free participation in the game process.

But would not such a refusal from the service to the law of production and reproduction mean unavoidable economic pullback, which will inevitably impact on the conditions of existence of the individuals? Marcuse does not exclude the prospect of such a rollback, but believes that it will be negligible and inconsequential in terms of conditions of free realization of genuine human needs, because the possibilities to achieve and maintain these conditions are present in the civilization for a long time.

Following Reich, he writes about the need to abolish the old morality, but morality as such can not and should not be obviated, it must be turned over. People in non-repressive civilization are guided by a new libidinal morality, which is not based on the rationality of production and reproductive genital sexuality, as the old morality was, but on the rationality of joy, which also has its own comprehensible structure. However, won't a society of liberated eros be the one of maniacs and rapists? In answering this question, and reminding us that sexual violence is usually generated by repression and is ill product of repressed eroticism, Marcuse introduces yet another instance in the model of the individual psyche, proposed by Freud: the Super-Id. As well as the Super-Ego Super-Id is the internal control authority, but does not come from repressive norms and ideals transferred into the subject, but because of the inclination to the self-restraint that is inherent for a healthy desire. Boundless continual satisfaction dulls the pleasure itself, and in a situation where there is no external compulsion, the individual, playing, puts himself temporary limits, which make the subsequent pleasure considerably more intense, and the path to it - more interesting and fascinating.

\section{CONCLUSION}

Unconditional acceptance of the repressive hypothesis inevitably faces a number of difficulties and gives rise to new issues that replace the received answers. These questions relate to both specific provisions of the considered theories and their main conclusions.

One of the most controversial issues that we should deal is the problem of sexuality without coercion. If we agree with the thesis of Reich and Marcuse, claiming that healthy sexuality is not in need of authoritarian mechanisms to suppress it, the factual basis for the implementation of the healthy sexuality remains debatable. Reich writes about free realization of the natural sexual needs with the right partner, the possibility of which can be achieved in specific individual cases, but can we talk about the presence of $a$ suitable partner for each person? Even without taking into account certain demographic circumstances (such as statistical "ten girls per nine guys"), we are inclined to doubt whether all the individuals of the society could equally be the subjects of healthy / full-fledged sex life and sexual satisfaction, since sexuality is type-selective and sexual "attractiveness" (as object), even if usually socially and historically determined, cannot be equal because of psychophysiological differences (as well as others, including, for example, intellectual) between individuals. Reich states that natural sexuality, if freed, makes people more equal in their desires and pleasures, but this statement doesn't seem obvious enough.

We should also note that, in the same way as according to a known formula it is impossible to build communism in one country, the possibility of constructing a nonauthoritarian, nonrepressive society within certain boundaries without significant isolation from the rest countries is questionable. The project of embodied autarchy, autonomous and self-sufficient society, which is not influenced by and do not need to provide their own interests in the face of external forces, in the present conditions of international affairs seem plausible. Transformation of the entire globe in a non-repressive civilization is obstructed, at least, by the fact that many societies still are in poverty and deprivation and definitely cannot afford the failure of Promethean principle. Despite the enormous opportunities concentrated in the industrialized countries, it is hardly possible to assume their redistribution on a global scale in the foreseeable future.

Finally, how actually real is building a civilization without repression regardless of the problems listed above? Aren't such arguments are just a utopia? And if so, what is the value of such speculation? And here we should go back to Marcuse, who speaks about the role of imagination in relation to the principle of desire and the reality principle. Fantasy, according to Marcuse, does not negate the reality principle that put limits to the pleasure principle, but being different from the reality principle, it may gradually change the latter. Fantasy is unreal in its inconsistency to the reality, but it has very real transformative potential. One man's dream of an alternative social order stumbles on the principle of reality, but the more people begin to dream about something similar, the less illusory their dreams are and the more relative the reality principle is.

Repressive hypothesis, in one form or another still shared by many today, is not the only product of critical reflection on the position of eros in the economy of power. Another approach was proposed by the theories of discoursedisciplinary and symbolic control which certainly requires a special study.

\section{REFERENCES}

[1] Russell B. Marriage and Morals. - Bantam Books, New York, 1968.

[2] Freud S. A General Introduction to Psychoanalysis. - Horace Liveright, Inc., 1920.

[3] Reich W. The Sexual Revolution. - Farrar, Straus and Giroux, New York, 1974.

[4] Marcuse H. Eros and Civilization. - Beacon Paperback, 1974.

[5] Freud S. Totem and Taboo. - Routledge Classics, London and New York, 2001.

[6] Freud S. Group Psychology and the Analysis of the Ego. - The Hogarth Press, London, 1949. 
[7] Butler J. The Psychic Life of Power. - Stanford University Press, Stanford, 1997.

[8] Reich W. The Mass Psychology of Fascism. - Farrar, Straus and Giroux, New York, 1970.

[9] Fromm E. The Art of Loving. - HarperCollins Publishers, London, 1995.

[10] Marcuse H. One-Dimensional Man. - Routledge Classics, London and New York, 2002. 